may recur at any time, and, as is most probable, very suddenly; we can only hope that observers will be equal to the next occasion.

The Minor Planers.-Of the members of this group, in addition to the four older ones, Ceres, Pallas, Juno, and Vesta, at present favourably placed for observation, the brighter are Hera, Iris, and Melpomene; Hera and Melpomene are a little below the tenth magnitude, and Iris about 9.5 . The following are approximate positions for Greenwich midnight :--

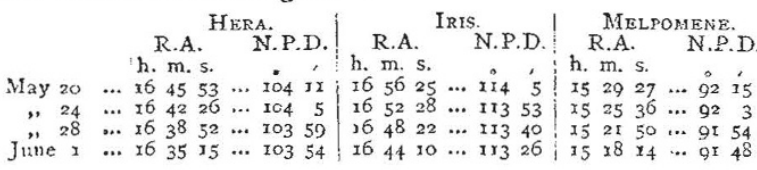

\section{THE GREENWICH TIME SIGNAL SYSTEM}

IN NATURE for April I of last year (vol. xi.p. 43I) we gave a description of the new Sidereal Standard Clock of the Royal Observatory at Greenwich. Fundamentally important as is this clock in all that concerns its relation to exact astronomical science, it performs also another and more immediately practical duty, that of regulating the time of great part of the United Kingdom. And we propose now to trace the connection existing between this purely astronomical clock and those by which the daily business of our lives is arranged.

A few worcs of preliminary history may not be uninteresting. Formerly, when, comparatively speaking, little communication existed between the people of different towns, each place kept its own local time. But when railways began to be extended through the country in all directions, such manner of reckoning time could not with any regard to convenience be followed in arranging the movements of trains. The adoption of one uniform system of counting time having, as regards railways, thus become a necessity, all towns in connection with railways, as a matter of convenience, fell sconer or later into the same system, one now universally followed. The time of the meridian of Greenwich is that employed. This selection was probably in part accidental. The railway authorities, when seeking for uniformity, would naturally be led to take as standard the time of the most infuential place, and so adopt metropolitan time, which happens to be, practically, Greenwich time. But however this may be, the selection was for another reason a happy one. The meridian of Greenwich is that from which longitudes are counted on all British maps, and Greenwich time having bec $n$ already long used by the navigator, means of oblaining a proper knowledge of it at seaports was very desirable. Its adoption for railways by facilitating the after-introduction of the time-signal system as now existing was therefore a fortunate circumstance.

The regular exhibition of accurate time for public use, by any kind of authoritative signal, was commenced at Greenwich in the year 1833 , when the first timeball was erected on the eastern turret of the ancient portion of the Observatory buildings, principally for the purpose of giving Greenwich time to chronometer maliers and seamen. It has been dropped every day since the year mentioned, excepting only during some periods of repair, and occasionally on days of violent wind. The ball, which is about five feet in diameter and painted black, is by mechanical means raised half-way up its mast at $5 \mathrm{~min}$. before $\mathrm{Ih}$. as a preparatory signal; at 3 min. before $\mathrm{Ih}$. it is hoisted to the summit. It drops at ih. true Greenwich mean solar time. Formerly it was discharged by an attendant who, watching a clock the error of which had been previously ascertained, pressed the ball-trigger at the proper instant, but since the year 1852 it has been discharged by automatic means, as will be explained further on. The first start of the ball, or its separation from the cross (indicating the cardinal points) immediately above, is very sudden, and is the phase to be noted; afterwards (to avoid injury to the building), a piston, connected by a long rod to the ball, falls into a nearly air-tight cylinder, and so checks its descent that it comes gently to rest at the foot of the mast.

Within a few years of the establishment of the Green. wich ball, others were erected at British observatories near to ports and harbours, as Edinburgh, Liverpool, Glasgow, \&c., principally also for the service of shipping. And such signal balls or equivalent mears of exhibiting time are now to be found at many observatories abroad, as for instance at the Cape of Good Hope, Madras, Bombay, Sydney, Melbourne, Mauritius, Quebec, Washington, \&c. Originally such time-balls could only be dropped at an observatory or institution at which time was determined by celestial observation, but on the intro. duction of the electric telegraph an observatory could be made the centre of a system from which, by galvanic means, time-balls could be dropped at, or time-signals given to, distant points.

On the first establishment of the electric telegraph in England, the connection of the Royal Observatory with the telegraphic system and its possible application to the daily distribution of time throughout the kingdom soon engaged the attention of the Astronomer Royal, but before things had come to any definite shape, the scheme for laying a submarine cable between England and France was proposed, and active steps taken to carry it out. The progress of this work was watched with interest by astronomers on both sides of the channel, and some of the active members of the Institute of France having expressed their earnest desire to take advantage of the new cable for galvanic determination of the difference of longitude between the Observatories of Paris and Greenwich, the Astronomer Royal became enabled in the year I852, principally with the assistance of Messrs. E. Clark (ot the then existing Electric Telegraph Company) and C. V. Walker (of the South-Eastern Railway Company), to establish the long-desired communications on the English side. The application of the telegraph to the direct determination of longitude will not, however, further concern us at present. As soon as telegraphic connection with the Royal Observatory was complete, the system of transmitting time signals from Greenwich for distribution by the Electric Telegraph Company on their lines was commenced, special apparatus having been for the purpose prepared both at Greenwich and Lordon. This we now proceed to describe.

The Mean Solar Standard Clock of the Royal Observatory, the principal clock of the whole time-signal system, erected in the year 1852 specially for the work, is always kept adjusted as nearly as possible to exact Greenwich mean time. It is a clock of Shepherd's construction, with seconds pendulum, and is maintained in action by galvanic means alone. But it works others sympathetically. The wire which carries the galvanic currents from the pendulum to the electro-magnets to drive the hands is continued, before returning to the battery, to other electro-magnets in connection with the hands of other dials in clifferent parts of the Observatory building, so that the hands on all the dials advance simultaneously, the forward motion of the whole system depending entirely on the one pendulum of the standard clock. Of these various clocks, one is fixed in the boundary-wall of the Observatory; it is daily consulted by great numbers of people, and will be familiar to every visitor to Greenwich Park. Several are placed in the Chronometer Room for use in the daily comparison of the Royal Navy and other chronometers, the difference between the time shown on one of these dials and that of any chronometer giving immediately the error of the chronometer without further calculation. Other dials are to be found in different office rooms in which accurate time is 1!ecessary. All these 
clocks, including a seconds' relay, $\alpha$, in the accompanying sketch, are driven by the galvanic current, but the standard clock further controls (by seconds' beats passing to London on a special wire from the seconds' relay) other clocks in London, on a principle, introduced nearly twenty years ago by $\mathrm{Mr}$. $\mathrm{R}$. $\mathrm{L}$. Jones, in which the galvanic force is used, not as the driving power, but as an auxiliary, to keep right clocks already going very nearly right, each by its own motive power. The principle has assumed various practical forms, but that proposed by Mr. Jones is generally employed, and is as follows :- The ordinary bob of the pendulum to be controlled being removed, a horizontal galvanic coil is substituted. At each swing of the pendulum the coil encircles permanent bar magnets fixed to the clock-case, and the galvanic current received at each second from the controlling clock circulates through the wire of the coil. Then (within certain rather wide limits), whether the clock to be controlled tends to lose or gain, the magnetic action produced between the coil and the permanent magnets at the instant of passage of the current so accelerates or retards the pendulum that the clock is maintained in perfect sympathy with the controlling clock.

Thus, at Greenwich various mean-time clocks within the Observatory, and several in London, depend on the one pendulum of the standard clock at Greenwich. But it is a condition that the clocks shall continue to show exact Greenwich time, and as no pendulum will perform with the necessary accuracy for any long period, it becomes essential to provide convenient means of making periodical correction. The plan used at Greenwich is as follows :- To the pendulum of the Mean Solar Standard is attached a slender bar magnet about five inches long, carried parallel to the rod by an arm projecting forwards from it. Immediately below, in a central and vertical position, and supported by the clock-case, is placed a hollow galvanic coil, the accelerating and retarding coil. The lower end of the magnet passes closely over the upper end of the coil. A galvanic current when passed through the coil imparts to it magnetic properties, rever. sion of the current reversing the direction of its magnetism. If the current be such as to cause attraction between the adjacent ends of the swinging magnet and fixed coil, the pendulum, carrying with it the whole sys. tem of clocks, will be accelerated ; an opposite current causing repulsion will conversely produce retardation. The only caution to be observed is that correction must not be made too rapidly, otherwise the controlled clocks,

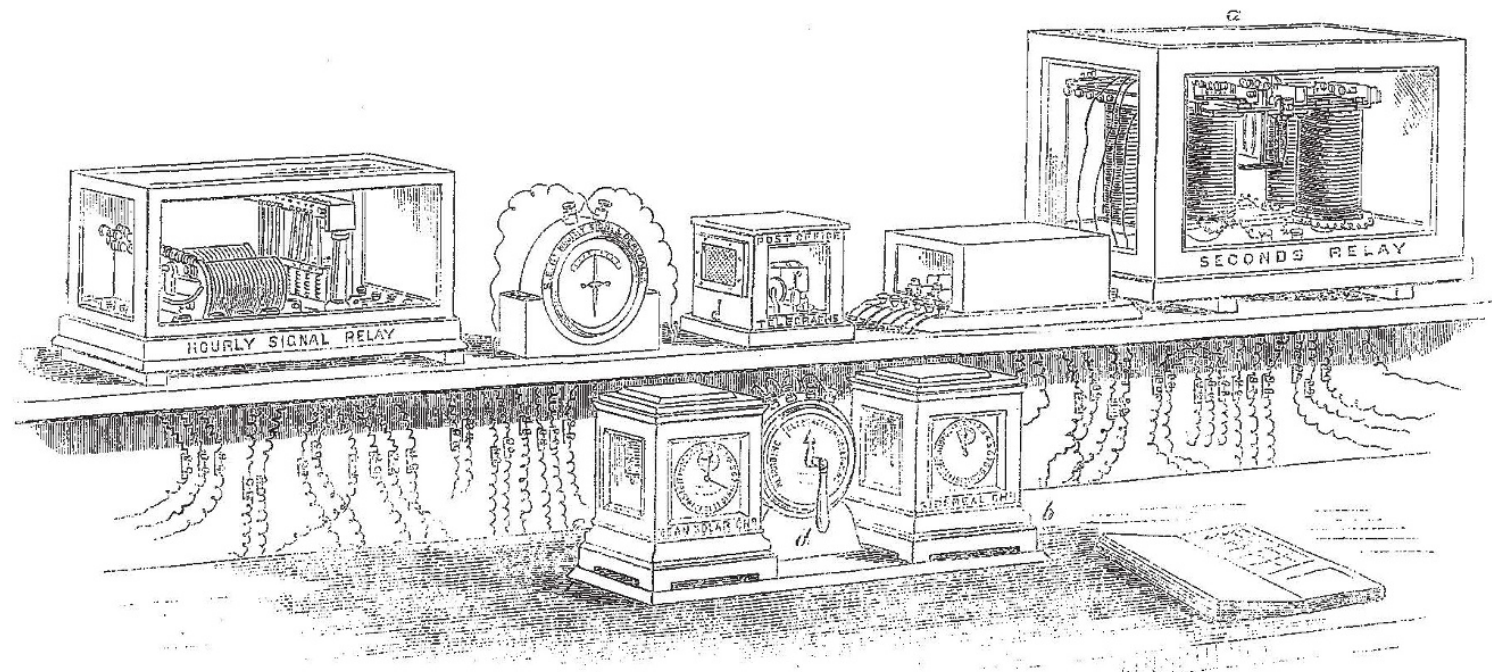

FIG. x.-Time Signal Apparatus in the Computing Room at the Royal Observatory, Greenwich.

which are, as it were, merely guided by the controlling current, might, so to speak, break away from control. As at present arranged, to produce an acceleration or. retardation of one second, the current must remain in action for about ten minutes.

Having described the mean-time system of clocks, and the magnetic appliance for correction of accumulated error, we have now to show how at any time the amount of correction required is determined. This makes it necessary to turn our attention to the system of sidereal clocks, and we shall now see how (as was stated at the beginning of this article) the Sidereal Standard is the real timekeeper of the country. This clock, with the system of sidereal clocks in connection therewith, was so fully described in the article already once referred to, that it will only be necessary to repeat here that amongst other things it galvanically registers its seconds on the paper of the revolving cylinder of the chronograph, and drives the sidereal chronometer $b$, situated on a certain desk in the Computing Room. Without going into further exjlanation it will be understood that, selecting a proper star of the Nautical Almanac list, the transit of which over the meridian has been observed with the transit circle and registered on the chronograph the times of its passing the several wires are extracted from the chronograph record, and the mean taken, which being corrected for the small errors of position of the instrument, and also (as the observations are taken by various observers) for "personal equation," the true clock-time of meridian passage, reduced to one standard, is found. The difference between this and the Nontical Almande right ascension of the star for the day gives the error of the sidereal standard, which is also the error of the siclereal chronometer $b$. Unlike the mean-time clocks (which are required always to show true time), the error of the sidcreal clocks is allowed to accumulate, and correction applied as necessary in any calculation in which time by one of the sidereal clocks enters.

Near to the sidereal chronometer $b$ there is placed, on the same desk in the Computing Room, a mean solar chronometer, c, sympathetic with the Mean Solar Standard. Between these chronometers is fixed a commutator, $d_{3}$, by means of which a galvanic current can be thrown into the accelerating and retarding coil of the Mean Solar Standard. When the commutator index stands in the position shown in the drawing no action takes place; when turned to the right the current accelerates the clock; when turned to the left it retards the clock. To ascertain at any time the 
amount of correction required, the two chronometers are compared, usually by watching for a coincidence of beats. Knowing the error of the sidereal standard, by astronomical observation as described, the true sidereal time of comparison becomes known; the corresponding mean solar time is then easily calculated, and the error of the mean solar system of clocks immediately found. The commutator handle is then turned to throw a battery current into the accelerating and retarding coil, such as will attract or repel the pendulum magnet of the Mean Solar Standard, according as the clock is found to be slow cr fast. The Mean Solar Standard and the various clocks in sympathy with it (those driven by it at Greenwich and those controlled by it at London) all receive the same correction, and are all brought to exact Greenwich mean time. By the arrangement described it will be seen that the Superintendent of the Time Department can at any time refer the Mean Solar system of clocks to the Sidereal Standard, and find and correct the error of the Mean Solar Standard and the whole system of mean solar clocks, whilst engaged in his ordinary office duties, and witkout moving from his position in the Computing Room. Correction is usually made every morning before Ioh. A.M. (because at that hour an important distribution of time takes place), and again before rh. P.M. (another important hour as regards time signals). The correction required is usually only a small fraction of a second.

Having shown how the error of the Sidereal Standard at Greenwich is found by astronomical observation, and from it that of the Mean Solar Standard, and lastly, how the latter clock is adjusted to exact time, we now proceed to describe the arrangements for giving time signals to the external world. A galvanic circuit passes through the Mean Solar Standard, but is broken in the clock in two places; one of these is united from about half a minute before to about half a minute after the minute hand marks sixty, and the other when the seconds hand indicates sixty seconds precisely. Both breaks can therefore only be together united at the cominencement of each hour, and then only can a current pass. Each hourly current acts upon two electro-magnets. One of these automatically discharges the Greenwich time-ball at $\mathbf{I h}$. daily ; the other is the electro-magret of the hourly signal relay (shown to the left in the drawing) which completes various independent circuits, each in connection with a separate line of wire. One of these is in communication with the central telegraph station of the General Post Office, London; another extends to the London Bridge Station of the SouthEasten Railway Company. Along each line a galvanic signal passes hourly from the Observatory, day and night for further transmission by apparatus under the control of other parties, and at this point (excepting in the case of the Deal time-ball to be hereafter spoken of ) the special responsibility of the Observatory terminates. The small bell and galvanometer in the drawing marked respectively "Post Office Telegraphs" and "S.E.R. Houtly Signals," indicate at the Observatory the passage of the signals on these wires.

\section{(To be continued.)}

\section{THE OPENING OF THE LOAN COLLECTION}

$7 \mathrm{HE}$ Loan Collection was auspiciously opened on Saturday last by the visit of the Queen, and that it has exceeded all expectations is sufficiently shown by the opinions of the public press, which we have collected in another page. The Queen's visit is admitted on all hands to have been $\widetilde{a}$ complete success. Her Majesty herself, the Empress of Germany, and the other distinguished personages who accomparied her, showed a genuine interest in the collection, and especially in those apparatus to which their attention was particularly drawn. The Times is "authorised to say that not only did her Majesty express to the Lord President of the Council, the Duke of Richmond, her gratification with the exhibition and with its success - exceeding any that could possibly have been anticipated of it-but that her Majesty desired to make known how much she was gratified by the manner of her reception and by the solicitude with which her visit was made interesting by the several scientific men who explained to her the nature of the objects exhibited."

Besides the German Empress, the Queen was accompanied by the Princess Beatrice, the Duke of Edinburgh, the Duke of Cambridge, Prince Edward of Saxe-Weimar, and among others who accompanied the Royal party during their tour round the collection were the Duke of Sutherland, the German, Austrian, Russian, and French and Spanish Ambassadors, the Italian Minister, the United States Chargé d'Affaires, besides a considerable number of the most eminent representatives of British and Foreign science, most of the members of the several committees, and many of the exhibitors.

The Queen was received at the south-eastern entrance to the Exhibition by the Duke of Richmond and Gordon and the Vice-President of the Committee of Council on Education, Lord Sandon, M.P., by the Commissioners of the Exhibition of $185 \mathrm{I}$, upon whose premises the Exhibition is held, and by the members of the Duke of Devonshire's Committee on Scientific Instruction.

The Duke of Richmond and Gordon escorted the Queen round the Exhibition, pointing out objects of interest, and as the Queen entered each division of the galleries, gentlemen conversant with the various branches of science had the honour of being presented and of explaining to their Majesties and Highnesses the objects exhibited.

The Educational Collection was first examined, M. Heard showing the curious and extensive Russian pedagogical collection. In the Mechanical Section the famous primitive locomotives "Puffing Billy" and the "Rocket" attracted considerable attention. In this section also the ship Faraday was described by Dr. C. W. Siemens, who at the same time explained his bathometer, recently described in NATURE. The German ironclad, König Wilhein, and other beautiful models illustrating the applications of science to shipbuilding, including a model of the Serapis, were described by Mr. E. J. Reed and the Duke of Edinburgh. In this same section Mr. W. Froude showed his models of the hulls of ships in solid paraffin, by which the valuable experiments were made which were recently described by him at length in NATURE. Prof. Tyndall's explanation of the lighthouses and fog-horns excited considerable interest, the Siren fog-horn being sounded to illustrate the usefulness of the signal. In the Fish Museum Mr. Frank Buckland was ready to explain the many interesting objects and processes shown there. fis the party passed into the gallery of Electricity and Magnetism, the enharmonic organ of Perronet Thomson was heard from above playing "God save the Queen." In the section just mentioned $M$. Breguet, of Paris, gave a brilliant display' of the electric light, while Prof. Carey Foster explained the great Haarlem natural magnet. Mr. Gramme's magneto-electric machines were shown Spottiswoode, and various telegraphic instruments by by Mr. Culley. As her Majesty proceeded leisurely through the collection, Sir William Thomson showed his wonderfully ingenious tide-calculating machine, Joule's apparatus for researches in heat, and an apparatus for deep-sea soundings. Prof. Kennedy exhibited the important collection of kinematic models sent by Prof. Reuleaux, of the Royal Technical Academy, Berlin. The Walter type-composing machine was explained by Mr. J. C. Macdonald, Sir Joseph Whitworth described his millionth-of-an-inch measuring apparatus, while $\mathrm{Mr}$. Chisholm explained various standard measures, a fine collection of standards made for the Russian Govern. 